\title{
Dynamically Monitoring the Photodeposition of Single Cocatalyst Nanoparticles on Semiconductors via Fluorescence Imaging
}

\author{
Hua Su and Wei Wang*
}

State Key Laboratory of Analytical Chemistry for Life Science, School of Chemistry and Chemical Engineering, Nanjing University, Nanjing 210023, China

*Corresponding author: Wei Wang, E-mail: wei.wang@ @ju.edu.cn

\section{Table of contents}

\section{Materials and methods}

1.1 Materials and characterization

1.2 Fluorescence imaging of $\mathrm{Co}_{\mathrm{x}} \mathrm{P}$ photodeposition and data analysis

\section{Supporting figures}

Figure S1. SEM and absorbance characterizations of $g-\mathrm{C}_{3} \mathrm{~N}_{4}$ sheets.

Figure S2. Redox property of $\mathrm{NaH}_{2} \mathrm{PO}_{2}$ and energy level position of $g-\mathrm{C}_{3} \mathrm{~N}_{4}$ sheets and CdS NWs.

Figure S3. EDS characterization of the $\mathrm{Co}_{\mathrm{x}} \mathrm{P} / g-\mathrm{C}_{3} \mathrm{~N}_{4}$ composites.

Figure S4. Correlation of FL decay kinetics and evolution of $F W H M^{3}$ and schematic illustration of the electron transfer between a photocatalyst and the $\mathrm{Co}_{x} \mathrm{P}$ cocatalyst.

Figure S5. Effect of laser power on the $\mathrm{Co}_{\mathrm{x}} \mathrm{P}$ photodeposition kinetics on $g-\mathrm{C}_{3} \mathrm{~N}_{4}$.

Figure S6. Effect of $\mathrm{Co}^{2+}$ concentration on the $\mathrm{Co}_{\mathrm{x}} \mathrm{P}$ photodeposition kinetics on $g-\mathrm{C}_{3} \mathrm{~N}_{4}$.

Figure S7. Effect of laser power on the apparent induction time of $\mathrm{Co}_{\mathrm{x}} \mathrm{P}$ photodeposition on $g-\mathrm{C}_{3} \mathrm{~N}_{4}$. 
Figure S8. Statistical analyses of the photodeposition kinetics of $\mathrm{Co}_{\mathrm{x}} \mathrm{P}$ cocatalysts on $g-\mathrm{C}_{3} \mathrm{~N}_{4}$ sheets. Figure S9. Photo-induced dissolution of the as-deposited $\mathrm{Co}_{\mathrm{x}} \mathrm{P}$ cocatalysts in $\mathrm{HNO}_{3}$.

Figure S10.Programmable photodeposition and photo-induced dissolution of $\mathrm{Co}_{\mathrm{x}} \mathrm{P}$ on $g-\mathrm{C}_{3} \mathrm{~N}_{4}$ sheets. Figure S11. Dynamical FL imaging of the photodepostion of $\mathrm{Co}_{\mathrm{x}} \mathrm{P}$ cocatalysts on single CdS NWs.

\section{Supporting references}

\section{Materials and methods}

\subsection{Materials and characterization}

$g-\mathrm{C}_{3} \mathrm{~N}_{4}$ powders (XFI10, NO. 100548) were purchased from Jiangsu XFNANO Materials Technology Co., Ltd (Nanjing, China) and further ultrasonically exfoliated prior to use. Typically, $10 \mathrm{mg}$ of $\mathrm{g}-\mathrm{C}_{3} \mathrm{~N}_{4}$ powders were dispersed in $\sim 30 \mathrm{~mL}$ pure water and placed in an ultrasonic bath over $1 \mathrm{~h}$ (Thermal fisher, FB15051). After discarding the supernatants and largely-sized aggregates, $g-\mathrm{C}_{3} \mathrm{~N}_{4}$ sheets in the range of 5-20 $\mu \mathrm{m}$ were collected. CdS NWs were prepared by a previously reported solvothermal method in ethylenediamine (99\%, Alfa Aesar), with cadmium nitrate ( $\geq 98.5 \%$, Alfa Aesar) and thiourea ( $\geq 99.0 \%$, Sigma Aldrich) as the precursors. ${ }^{1}$ Cobalt nitrate hexahydrate (99.99\%), sodium hypophosphite $(99.0 \%)$ and nitric acid (65-68\%) were bought from Aladdin (Shanghai, China).

Scanning electron microscopy (SEM) characterizations were conducted on Phenom Pro Desktop SEM and JSM-7800F equipped with an energy dispersive spectrometer (EDS, Oxford instruments). Shimadzu UV-3600 spectrometer was used to record the absorbance spectrum of $g-\mathrm{C}_{3} \mathrm{~N}_{4}$ power. Cyclic voltammetric $(\mathrm{CV})$ characterization of $\mathrm{NaH}_{2} \mathrm{PO}_{2}$ was performed at $25{ }^{\circ} \mathrm{C}$ with a $\mathrm{CHI} 760 \mathrm{E}$ electrochemical analyzer (Chenhua Instruments Co., China), with Au disk, glassy carbon and $\mathrm{Ag} / \mathrm{AgCl}$ as the working electrode, counter electrode and reference electrode, respectively. During the measurements, the $\mathrm{pH}$ of $\mathrm{NaH}_{2} \mathrm{PO}_{2}$ aqueous solution $\left(2 \mathrm{M}, \mathrm{O}_{2}\right.$-free) was maintained at 7.0 (buffered with $0.2 \mathrm{M}$ of HAc-NaAc solution), with $\mathrm{Na}_{2} \mathrm{SO}_{4}(0.1 \mathrm{M})$ as the supporting electrolyte.

\subsection{Fluorescence imaging of photodeposition and data analysis}

Fluorescence (FL) imaging was carried out on an Olympus IX83 inverted microscope equipped with a TIRF illuminator (Olympus). A 405-nm or 488-nm laser (OBIS, Coherent) was focused onto the back focal plane of a 100x-TIRF oil-immersed objective (Olympus, numerical aperture, 1.2) by the TIRF apparatus, and vertically directed onto a glass coverslip with a beam diameter of $\sim 120 \mu \mathrm{m}$. The laser acted as the light source to simultaneously trigger the photodeposition of $\mathrm{Co}_{\mathrm{x}} \mathrm{P}$ cocatalysts and to excite the semiconductor for FL imaging. A commercially available Olympus 405-nm cellFRAP was used for programmable photodeposition and photo-induced dissolution of $\mathrm{Co}_{\mathrm{x}} \mathrm{P}$ 
cocatalysts on $g-\mathrm{C}_{3} \mathrm{~N}_{4}$ sheets. An EMCCD camera (Andor DU897, 512×512 pixels, $16 \mu \mathrm{m} \times 16 \mu \mathrm{m}$ pixel size) was used to record the FL images of the semiconductors.

The $150 \mu \mathrm{m}$-thick glass coverslips (Thermo Fisher, No. 1 type, catalog No. 12-542-B) were used as the substrate, which was successively washed by acetone, ethanol and water in an ultrasonic bath, and then assembled with a polydimethylsiloxane cell (PDMS, FlexiPERM micro 12) as the reaction chamber for FL imaging. A laser power density of $\sim 350 \mathrm{~W} \mathrm{~cm}^{-2}$ was usually used throughout the experiments. Before photodeposition, $g-\mathrm{C}_{3} \mathrm{~N}_{4}$ sheets or $\mathrm{CdS} \mathrm{NWs}$ were ultrasonically dispersed in pure water and added to the PDMS cell. After a desired density of photocatalysts bounded onto the coverslip, the dispersion solution was carefully discarded. Followingly, a mixture solution containing $\mathrm{Co}\left(\mathrm{NO}_{3}\right)_{2}(2 \mathrm{mM})$ and $\mathrm{NaH}_{2} \mathrm{PO}_{2}(800 \mathrm{mM})$ was added for photodeposition, while $3.5 \mathrm{M}$ of $\mathrm{HNO}_{3}$ was used to dissolve the as-formed $\mathrm{Co}_{\mathrm{x}} \mathrm{P}$ cocatalysts.

The obtained FL images were analyzed by the commercially available MATLAB software. The FL kinetics of each $\mathrm{Co}_{\mathrm{x}} \mathrm{P}$ nanoparticle was obtained by subtracting its neighbouring background at each frame and then fitted with an exponential function, while the corresponding full width at half maximum (FWHM) was extracted by a two-dimensional Gaussian fitting.

\section{Supporting figures}
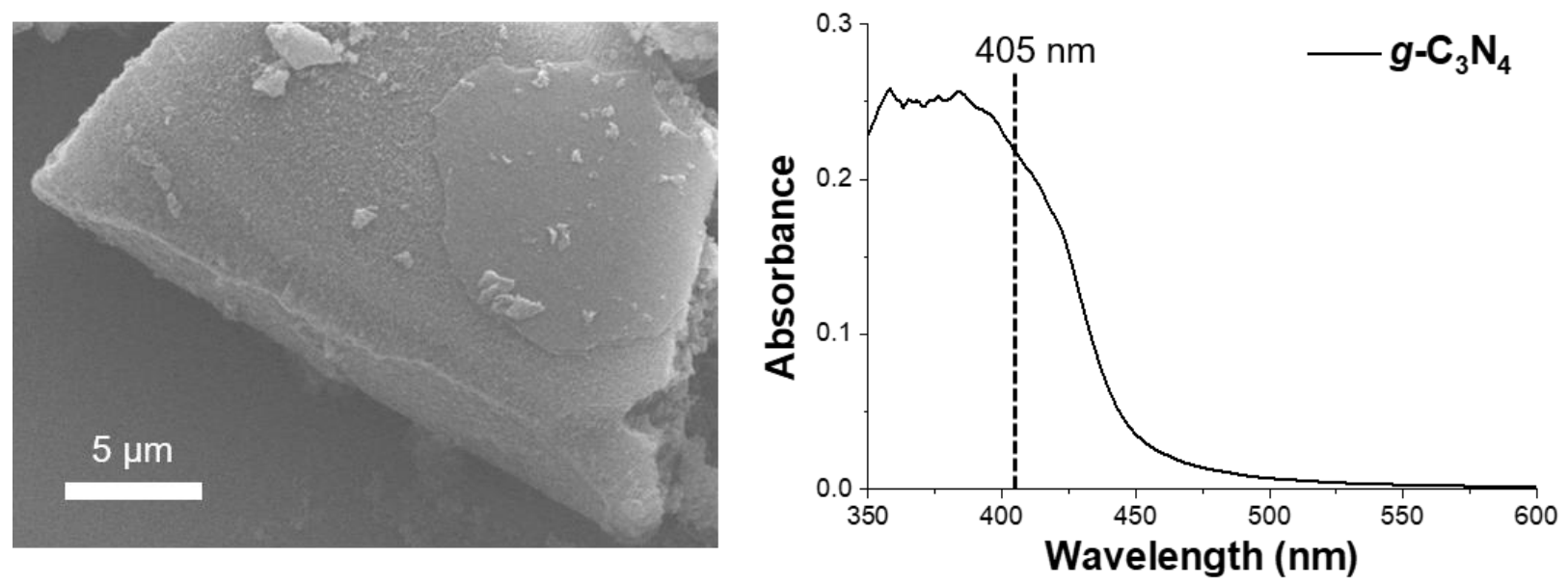

Figure S1. SEM and absorbance characterizations of $g-\mathrm{C}_{3} \mathrm{~N}_{4}$ sheets. After an ultrasonic exfoliation and purification, $g-\mathrm{C}_{3} \mathrm{~N}_{4}$ sheets with relatively large lateral sizes were obtained for the photodeposition. UV-vis absorbance measurement indicated that $g-\mathrm{C}_{3} \mathrm{~N}_{4}$ sheets exhibited strong absorbance to blue light, and therefore, a 405-nm laser was used to trigger the photodeposition of $\mathrm{Co}_{\mathrm{x}} \mathrm{P}$ cocatalysts. Scale bar: $5 \mu \mathrm{m}$. 

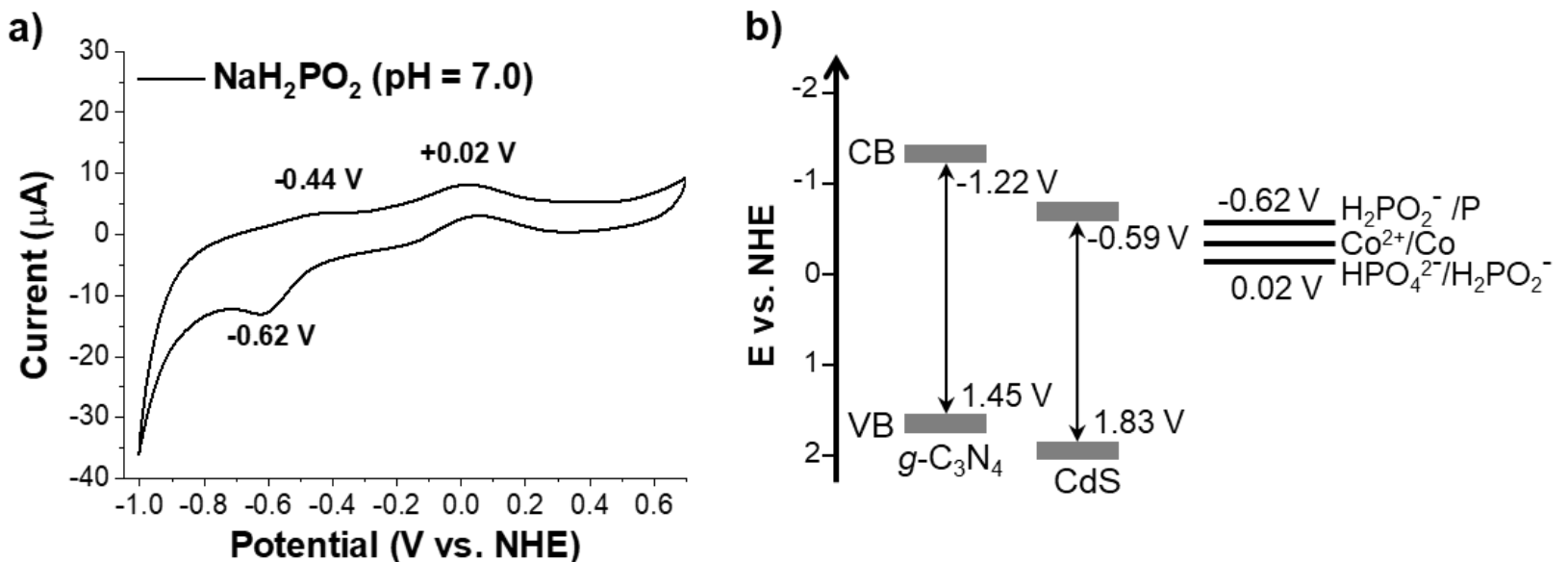

Figure S2. a) Redox property of $\mathrm{NaH}_{2} \mathrm{PO}_{2}$. CV curve of $\mathrm{NaH}_{2} \mathrm{PO}_{2}$ shows a significant reductive peak at $0.62 \mathrm{~V}\left(\mathrm{H}_{2} \mathrm{PO}_{2}^{-} / \mathrm{P}\right)$, and two oxidative peaks at $-0.44 \mathrm{~V}$ and $+0.02 \mathrm{~V}$, which can be ascribed to oxidative products of $\mathrm{HPO}_{3}{ }^{2-}$ and $\mathrm{HPO}_{4}{ }^{2-}$, respectively. ${ }^{2}$ b) Energy level position of $g-\mathrm{C}_{3} \mathrm{~N}_{4}$ sheets and $\mathrm{CdS}$ NWs. The conduction band minima of $g-\mathrm{C}_{3} \mathrm{~N}_{4}$ and $\mathrm{CdS}$ are more negative than the reductive potential $\mathrm{of}_{2} \mathrm{H}_{2} \mathrm{PO}_{2}{ }^{-}$and $\mathrm{Co}^{2+}$, while the valence band maxima of semiconductors are much more positive than that of $\mathrm{H}_{2} \mathrm{PO}_{2}{ }^{-3} \cdot{ }^{-4}$ Noted that the reductive potential of $\mathrm{Co}^{2+} / \mathrm{Co}$ was $\sim-0.28 \mathrm{~V}$ according to the reference. ${ }^{5}$ Upon illumination, $\mathrm{H}_{2} \mathrm{PO}_{2}{ }^{-}$ and $\mathrm{Co}^{2+}$ are reduced by the photogenerated electrons, which further evolve into nearly zero-valent state $\mathrm{Co}_{x} \mathrm{P}$ cocatalysts on $g-\mathrm{C}_{3} \mathrm{~N}_{4}$ and $\mathrm{CdS}$, and the photogenerated holes were scavenged by excess $\mathrm{H}_{2} \mathrm{PO}_{2}{ }^{-}$ions.

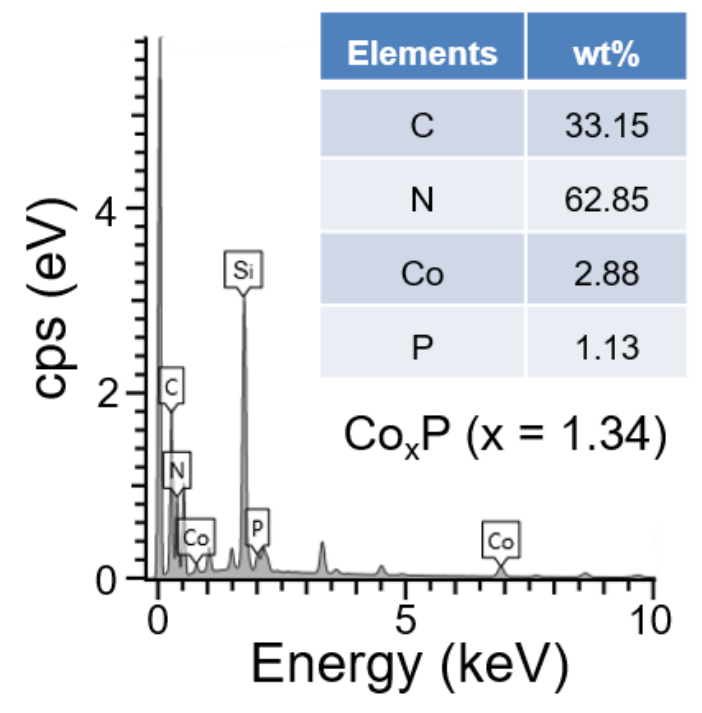

Figure S3. EDS characterization of the $\mathrm{Co}_{x} \mathrm{P} / g-\mathrm{C}_{3} \mathrm{~N}_{4}$ composites. EDS analysis confirmed the existence of cobalt and phosphorus elements, and an approximate $\mathrm{x}$ value of 1.34 . 

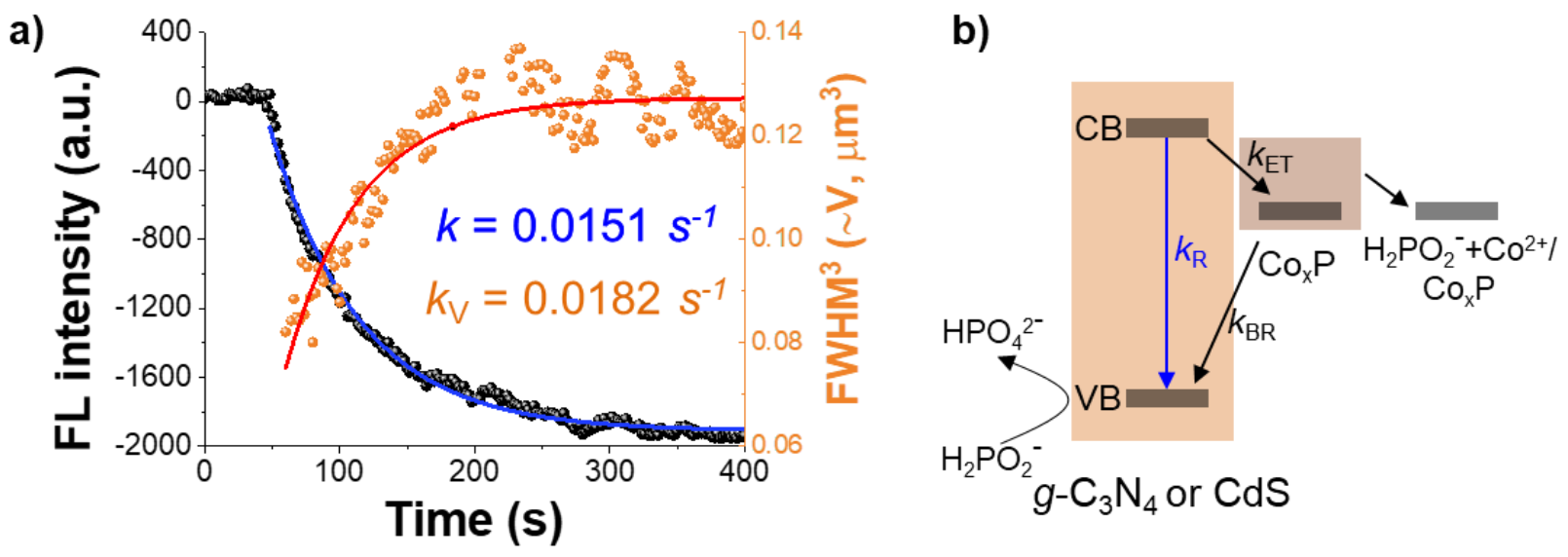

Figure S4. a) Correlation of FL decay kinetics and evolution of $F W H M^{3}$ (approximate to volume of $\mathrm{Co}_{\mathrm{x}} \mathrm{P}$ ) during photodeposition, both of which exhibited mono-exponentially behaviors. b) Schematic illustration of the electron transfer between a photocatalyst and the $\mathrm{Co}_{\mathrm{x}} \mathrm{P}$ cocatalyst (usually positively correlated with the volume of cocatalyst), which competes with the radiative recombination (i.e., leading to FL quenching) and usually possesses a faster kinetics ( ps vs. ns) ${ }^{6}$ Therefore, the monotonically increased electron transfer may lead to the mono-exponentially decayed FL intensity of $g-\mathrm{C}_{3} \mathrm{~N}_{4}$ sheets or CdS NWs during $\mathrm{Co}_{\mathrm{x}} \mathrm{P}$ growth.
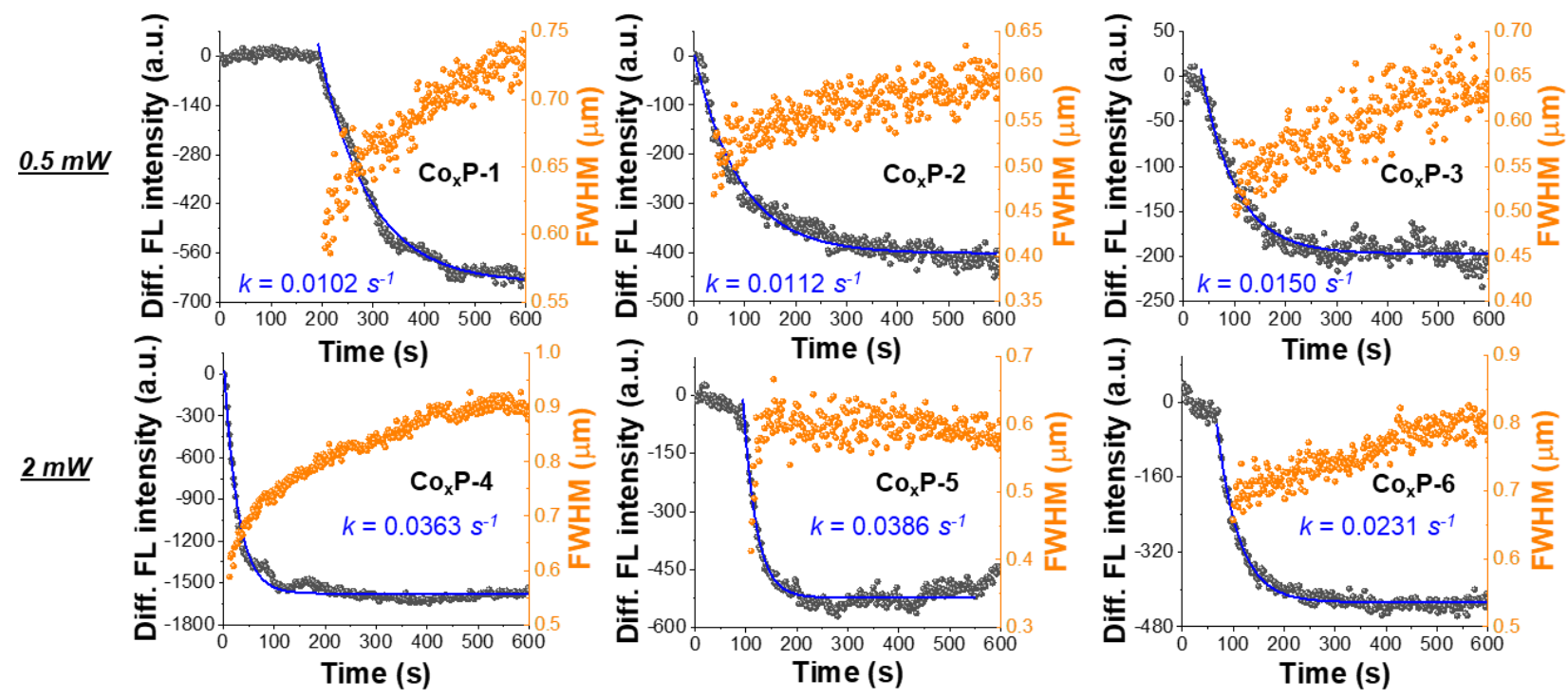

Figure S5. Simultaneously monitoring the FL decay kinetics and $F W H M$ evolution during $\operatorname{Co}_{x} \mathrm{P}$ photodeposition on $g-\mathrm{C}_{3} \mathrm{~N}_{4}$ at varied power of laser. Faster FL decay rate can be observed upon $2 \mathrm{~mW}$-laser illumination. All $\mathrm{Co}_{\mathrm{x}} \mathrm{P}$ nanoparticles show the tendency to a saturated $F W H M$ with time, suggesting the selflimited growth of cocatalysts during photodeposition. $\left[\mathrm{Co}^{2+}\right]=2 \mathrm{mM},\left[\mathrm{H}_{2} \mathrm{PO}_{2}^{-}\right]=0.8 \mathrm{M}$. 

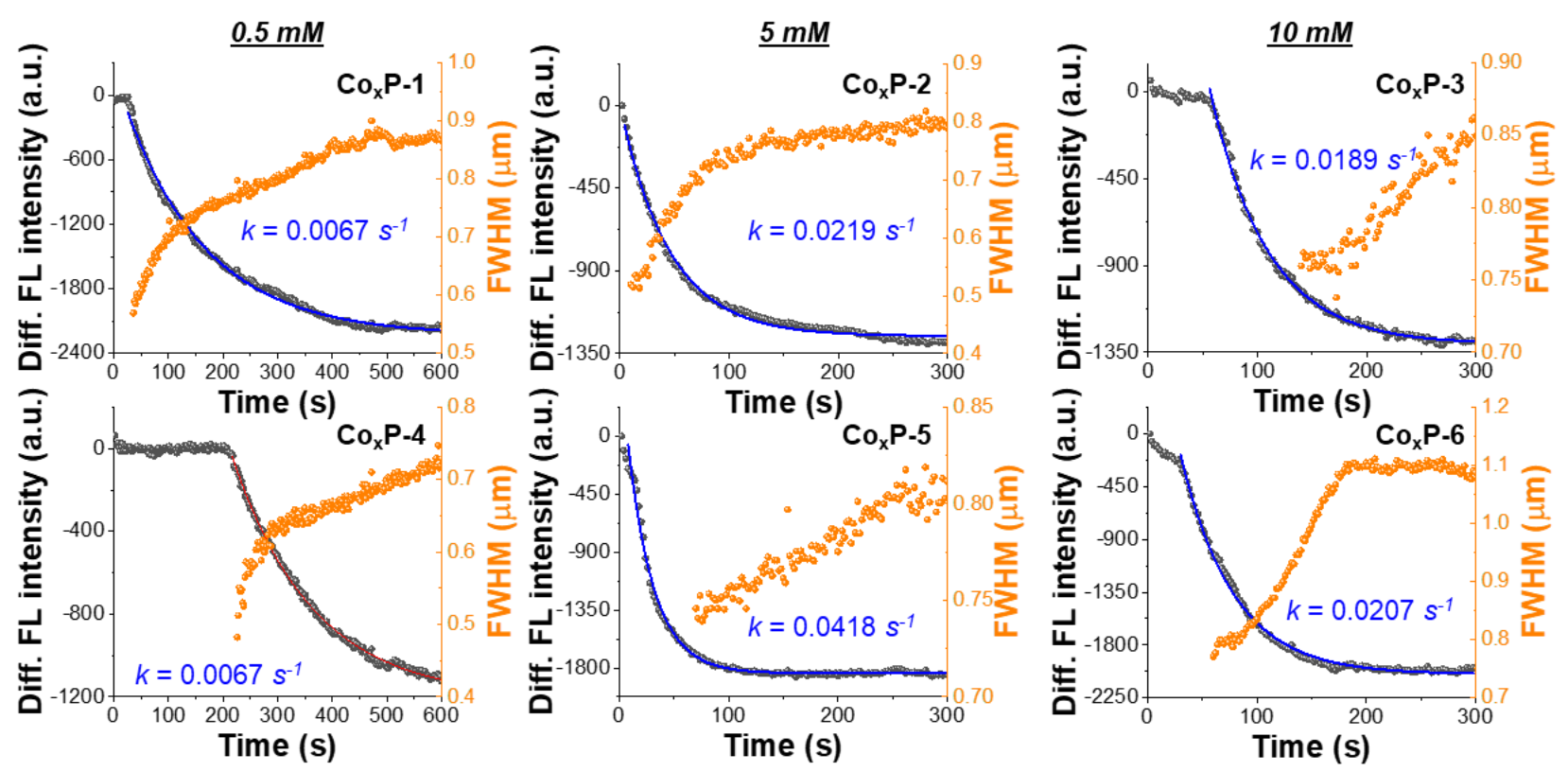

Figure S6. Simultaneously monitoring the FL decay kinetics and $F W H M$ evolution during $\operatorname{Co}_{x} \mathrm{P}$ photodeposition on $g-\mathrm{C}_{3} \mathrm{~N}_{4}$ at varied concentration of $\mathrm{Co}^{2+}$. FL decayed more slowly in the case of $0.5 \mathrm{mM}$ of $\mathrm{Co}^{2+}$, while a saturated $\mathrm{FL}$ decay rate can be observed for that of higher concentration (roughly equivalent to that of $2 \mathrm{mM} \mathrm{Co}^{2+}$ in the manuscript). All $\mathrm{Co}_{\mathrm{x}} \mathrm{P}$ nanoparticles show the tendency to a saturated $F W H M$ with time, suggesting the self-limited growth of cocatalysts during photodeposition $\left[\mathrm{H}_{2} \mathrm{PO}_{2}{ }^{-}\right]=0.8 \mathrm{M}$, laser power, $5 \mathrm{~mW}$.

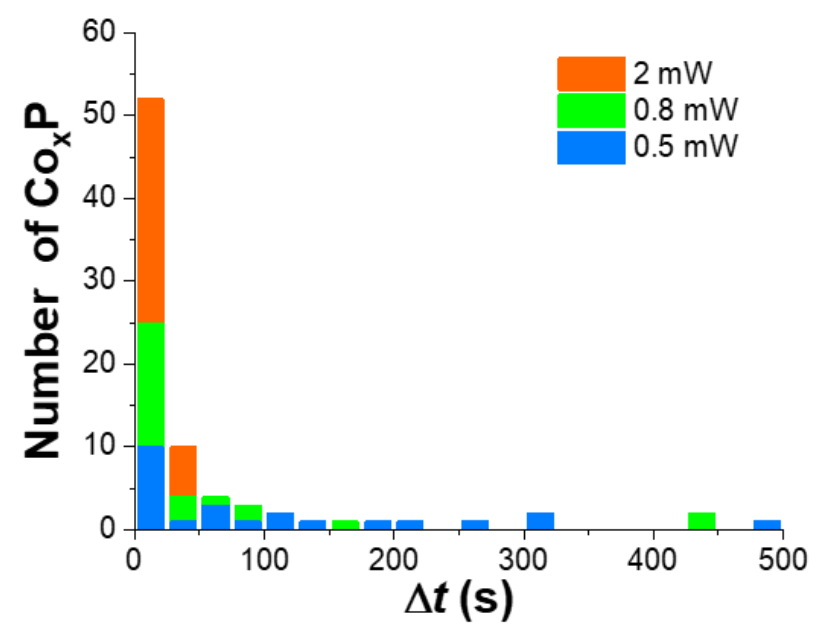

Figure S7. Effect of the power of 405-nm laser on the apparent induction time ( $\triangle t)$ of $\mathrm{Co}_{\mathrm{x}} \mathrm{P}$ photodeposition on $g-\mathrm{C}_{3} \mathrm{~N}_{4}$. There existed a significantly shortened $\triangle t$ with the increase of laser power, accompanied by an increased number of $\mathrm{Co}_{x} \mathrm{P}$ cocatalysts. This may be explained that higher power density of laser (supply of more electrons) promoted the more $\mathrm{Co}_{\mathrm{x}} \mathrm{P}$ nucleus to get over the energy barrier for growth, thus leading to a significant shortened $\triangle t .139 \mathrm{Co}_{\mathrm{x}} \mathrm{P}$ nanoparticles deposited on $19 \mathrm{~g}-\mathrm{C}_{3} \mathrm{~N}_{4}$ sheets were statistically analyzed. 

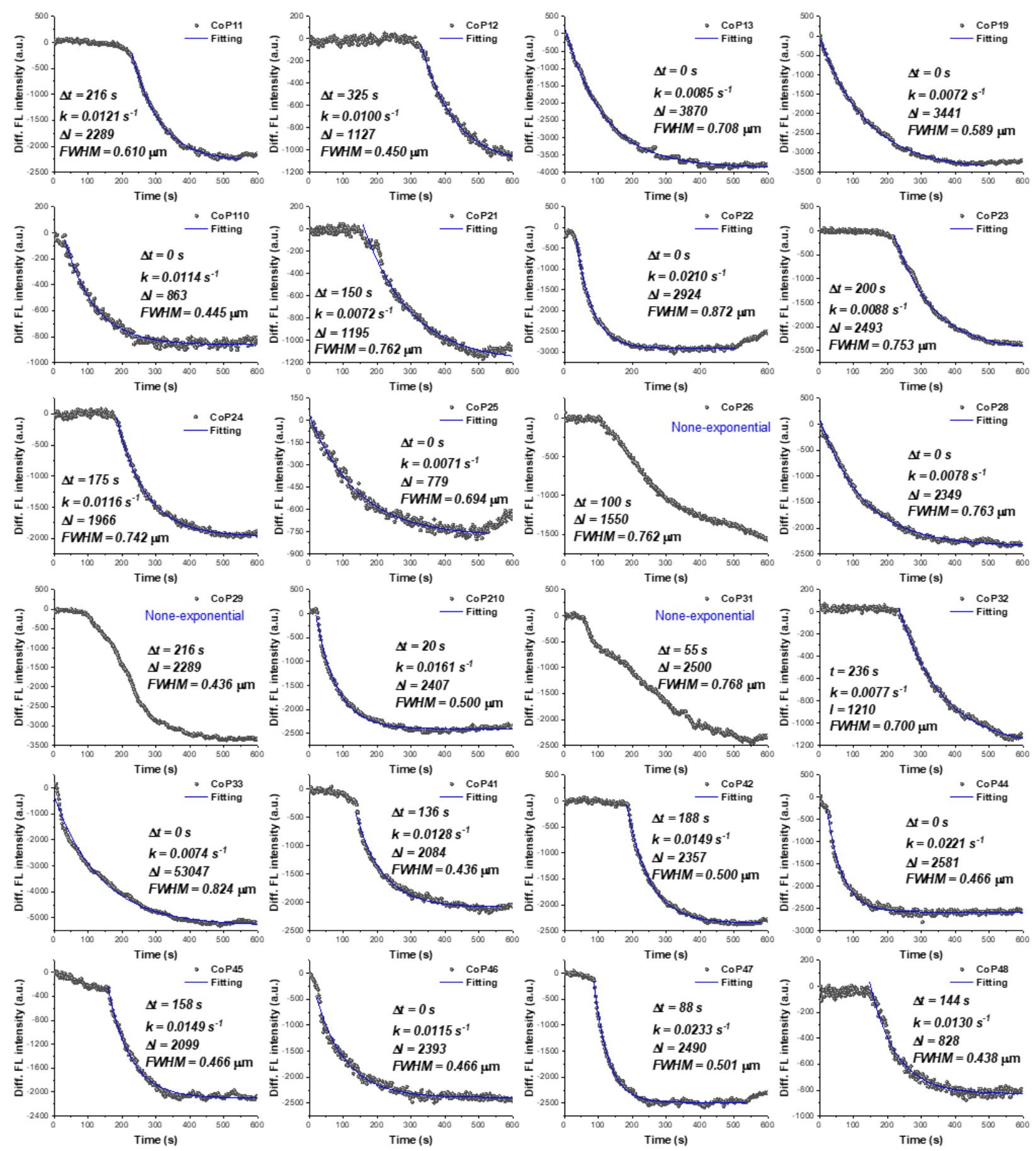

Figure S8. Statistical analyses of the photodeposition kinetics of $\mathrm{Co}_{\mathrm{x}} \mathrm{P}$ cocatalysts on $g-\mathrm{C}_{3} \mathrm{~N}_{4}$ sheets. $\triangle t, k$, $\triangle I$ and $F W H M$ was labeled in the kinetics curve of each $\mathrm{Co}_{\mathrm{x}} \mathrm{P}$ cocatalysts. The 21 of $24 \mathrm{Co}_{\mathrm{x}} \mathrm{P}$ nanoparticles exhibited mono-exponential kinetics, and more than a half of populations possessed the induction time. Importantly, the as-deposited $\mathrm{Co}_{\mathrm{x}} \mathrm{P}$ nanoparticles showed significant heterogeneities in deposition rate $\left(0.006-0.024 \mathrm{~s}^{-1}\right)$ and the $F W H M$ of FL quench $(0.4-0.9 \mu \mathrm{m})$. 

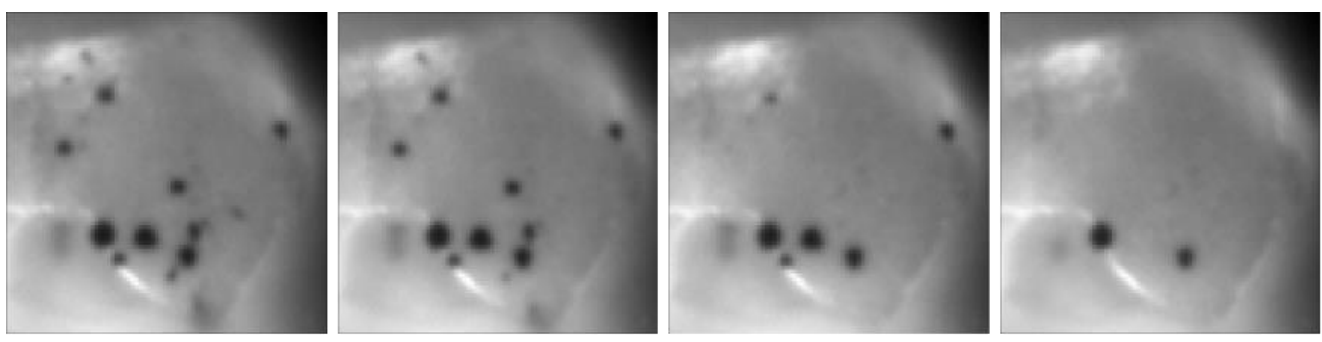

\section{After deposition}

\section{$\mathrm{HNO}_{3}$ treatment after} $15 \mathrm{~min}$ (w/o light)
Erasing - 2 min (light)
Erasing - $4 \mathrm{~min}$ (light)

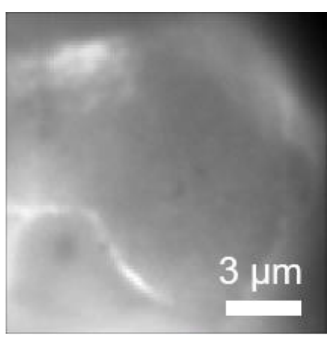

Erasing - 6 min (light)

Figure S9. Photo-induced dissolution of the as-deposited $\mathrm{Co}_{x} \mathrm{P}$ cocatalysts in $\mathrm{HNO}_{3}$. After a 15 -min immersion in $3.5 \mathrm{M} \mathrm{HNO}_{3}$, little changes occurred to the as-deposited $\mathrm{Co}_{\mathrm{x}} \mathrm{P}$ cocatalyst. Upon a $405-\mathrm{nm}$ laser illumination, however, the $\mathrm{Co}_{\mathrm{x}} \mathrm{P}$ cocatalysts were quickly dissolved with time and totally disappeared after 6 min, suggesting the proposed mechanism of photo-induced oxidative dissolution.

a)
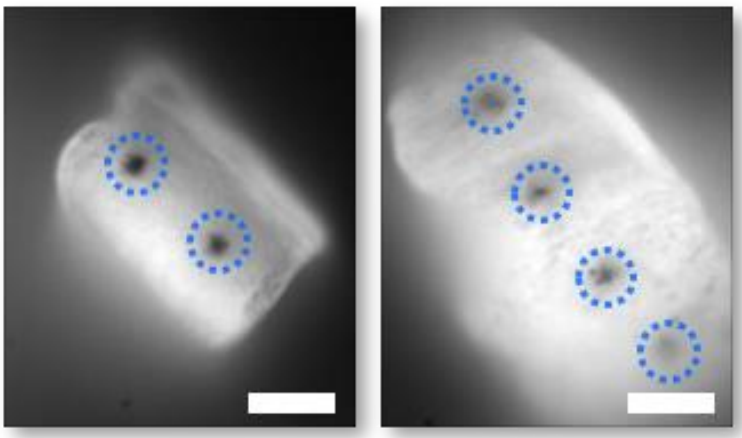

b)

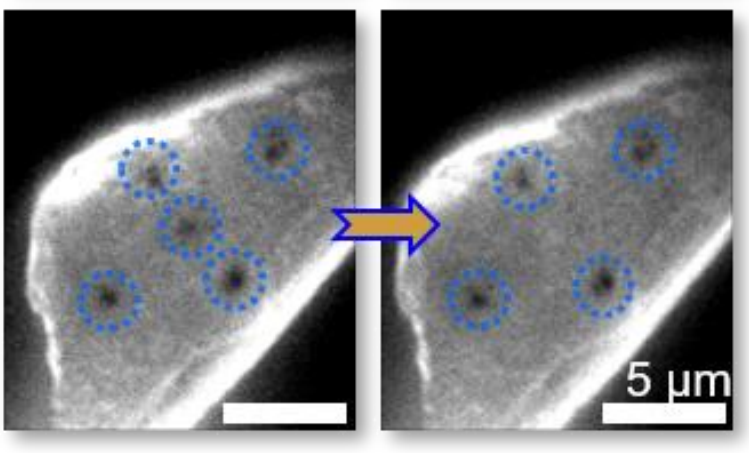

Figure S10. Programmable photodeposition (a) and photo-induced dissolution (b) of $\mathrm{Co}_{\mathrm{x}} \mathrm{P}$ cocatalysts on $g$ $\mathrm{C}_{3} \mathrm{~N}_{4}$ sheets. This was realized using an Olympus cellFRAP setup, in which the spot size of a $405-\mathrm{nm}$ laser was focused into $<1 \mu \mathrm{m}$. Condition: deposition, $3 \mathrm{~mW}$ for $2 \mathrm{~s}$; dissolution, $1 \mathrm{~mW}$ for $0.5 \mathrm{~s}$. Scale bar: $5 \mu \mathrm{m}$. 
a)
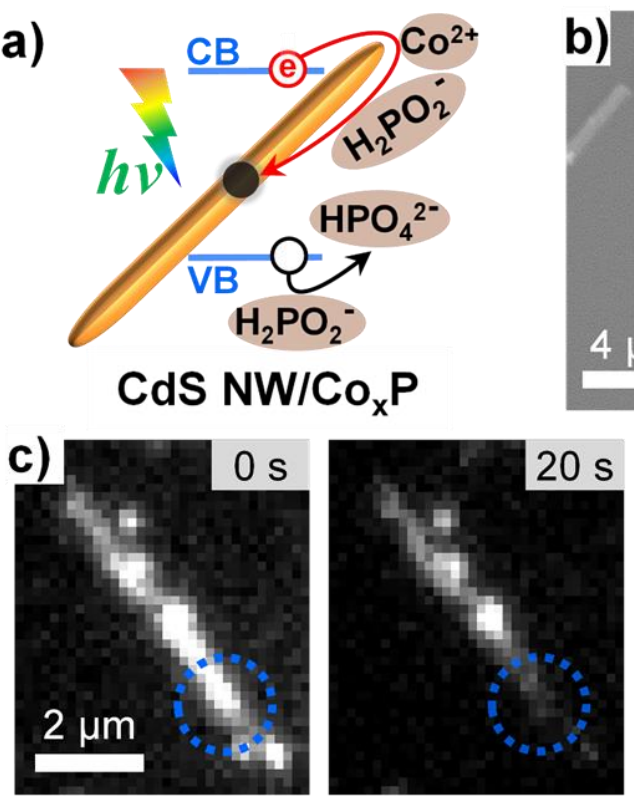

d)

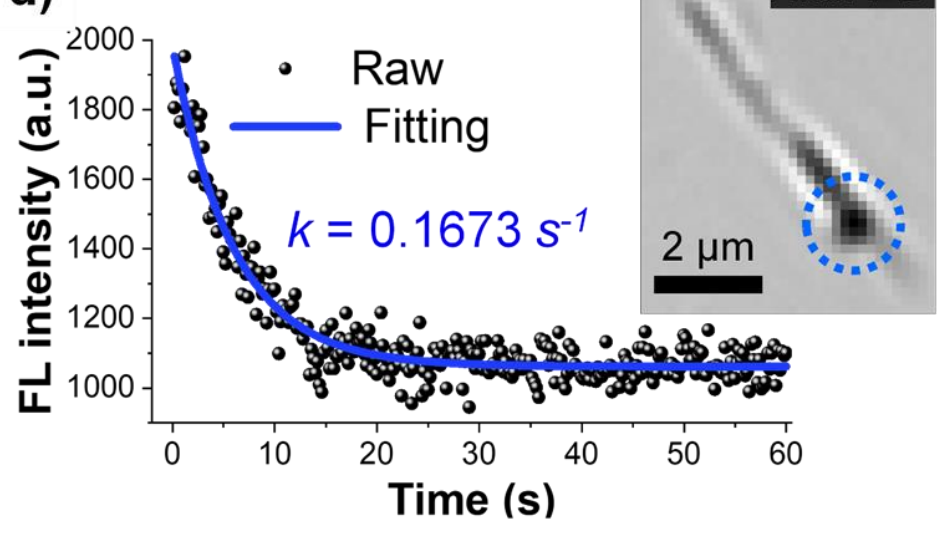

Figure S11. Dynamical FL imaging of the photodepostion of $\mathrm{Co}_{\mathrm{x}} \mathrm{P}$ cocatalysts on single CdS NWs. a) Schematic illustration of the photodeposition. b) Ex situ SEM characterization of the $\mathrm{Co}_{\mathrm{x}} \mathrm{P} / \mathrm{CdS}$ composites after deposition. c) Sequential FL images of a CdS NW during 60-s photodeposition and the BF image after the deposition. The location of the $\mathrm{Co}_{\mathrm{x}} \mathrm{P}$ nanoparticle deposited was marked with a blue dash circle. d) FL decay trajectory of the CdS NW during the growth of $\mathrm{Co}_{\mathrm{x}} \mathrm{P}$ nanoparticle, with a typical mono-exponential behavior.

\section{Supporting references}

(1) Jang, J. S.; Joshi, U. A.; Lee, J. S. J. Phys. Chem. C 2007, 111 (35), 13280-13287.

(2) Jin, Y.; Sun, D.; Yu, H.; Yang, D. Trans. IMF 2001, 79 (1), 38-40. 
(3) Zhang, J.; Chen, X.; Takanabe, K.; Maeda, K.; Domen, K.; Epping, J. D.; Fu, X.; Antonietti, M.; Wang, X. Angew. Chem. Int. Ed. 2010, 49 (2), 441-444.

(4) Zhu, Y.; Chen, J.; Shao, L.; Xia, X.; Liu, Y.; Wang, L. Appl. Catal., B 2020, 268, 118744.

(5) Saadi, F. H.; Carim, A. I.; Verlage, E.; Hemminger, J. C.; Lewis, N. S.; Soriaga, M. P. J. Phys. Chem. C 2014, 118 (50), 29294-29300.

(6) Ben-Shahar, Y.; Scotognella, F.; Kriegel, I.; Moretti, L.; Cerullo, G.; Rabani, E.; Banin, U. Nat. Commun. 2016, 7 (1), 10413. 